\title{
An indirect calorimetry system for ventilator dependent very low birthweight infants
}

\author{
J S Forsyth, Anna Crighton
}

\begin{abstract}
With neurodevelopmental outcome of very low birthweight (VLBW) infants being adversely affected by inadequate nutrition during the first few weeks of life, there is an urgent need for more specific nutritional data on the sick VLBW ventilator dependent infant. The development of a new mass spectrometry gas analysis indirect calorimetry system which is non-invasive and can operate over several hours or days is described. Technical evaluation of each of the components of the system indicates a total random error of $<5 \%$. Systematic error was determined using gas infusions which simulated carbon dioxide production and oxygen consumption. The relative error in the measurement of carbon dioxide production was $\leqslant 1.5 \%$ (coefficient of variation (CV) $6.0 \%$ )) with carbon dioxide infusion rates ranging from 3.86 to $13.98 \mathrm{ml} / \mathrm{min}$. The relative error in oxygen 'consumption' was $\leqslant 4.3 \%$ (CV $2.8 \%$ ) for infusions of oxygen at rates of 7.5 to $14.80 \mathrm{ml} / \mathrm{min}$. With nitrogen infusions simulating oxygen consumptions of 2.0 and $5.5 \mathrm{ml} / \mathrm{min}$ the relative error in the calculated nitrogen infusion was $1.5 \%$ (CV $4 \cdot 1 \%$ ) and $1 \cdot 4 \%$ (CV $5 \cdot 7 \%$ ) respectively. Clinical studies on 10 infants demonstrated a mean energy expenditure of $161.7 \mathrm{~kJ} / \mathrm{kg} /$ day and a respiratory quotient in excess of 1.0 . The energy expenditure of ventilated VLBW infants may be less than previously indicated and the energy mix and nitrogen content of parenteral nutrition regimens recommended for these infants may be inappropriate.
\end{abstract}

Nearly $1 \%$ of all infants have a birth weight of less than $1500 \mathrm{~g} .{ }^{1}$ Although the mortality of this group has greatly diminished in recent years, there is still significant morbidity. ${ }^{2}$ More than $60 \%$ of these very low birthweight (VLBW) babies suffer from respiratory distress syndrome and require artificial ventilation, ${ }^{3}$ the duration of which may be prolonged if the infant develops chronic lung disease. There has been recent concern that inadequate nutrition during this period may not only have a major effect on physical growth of the VLBW baby but may also significantly influence neurodevelopmental outcome. ${ }^{45}$

To date, interest in the nutritional status and management of the VLBW baby has concentrated on healthy growing infants, their energy expenditure and nutritional balance being estimated while receiving different feeding regimens. $^{6}$ Indirect calorimetry has been the method of choice as it is practicable and accurate for the spontaneously breathing infant. This method provides an estimate of oxygen consumption and carbon dioxide production from which the respiratory quotient (RQ) can be calculated. ${ }^{7}$ If simultaneous measurement of urinary nitrogen is made, fat, carbohydrate, and protein utilisation can be calculated. ${ }^{8}$ From these studies on healthy premature infants it has been suggested that the total energy intake for enterally fed infants should be in the region of $462-672 \mathrm{~kJ} / \mathrm{kg} /$ day, ${ }^{9}$ and $252-336 \mathrm{~kJ} / \mathrm{kg} /$ day for infants receiving parenteral nutrition. ${ }^{10}$

It cannot be assumed that this data is meaningful for the sick ventilator dependent infant. The overall work of breathing in these infants will be influenced by the contribution of ventilator support, the frequency of spontaneous respirations, and the compliance of the lungs. In adults, oxygen consumption is increased in trauma and sepsis, ${ }^{11}$ both of which are frequently present in sick infants. In healthy premature infants, $15-20 \%$ of energy expenditure may be due to spontaneous activity ${ }^{9}$; this is likely to be reduced in the sick and the more premature infant. The overall effect of all of these factors on total energy expenditure in sick ventilated infants is at present unknown.

The lack of calorimetry data on sick ventilator dependent infants is primarily related to the practice of using continuous flow ventilators for neonatal ventilation. These ventilators provide a continuous flow of oxygenated air across the proximal end of the endotracheal tube, thus allowing the inhalation of fresh gas if spontaneous respirations are present. With the continuous gas flows being in the region of 6-8 $1 / \mathrm{min}$, and the volume of oxygen consumed and carbon dioxide produced by the infant being only several $\mathrm{ml} / \mathrm{min}$, measurement of differences in gas concentrations between inspiratory and expiratory circuits requires a system of considerable accuracy and precision, particularly if the inspiratory oxygen concentration is high. An additional requirement of such a system is the ability to operate over several hours and to allow routine medical and nursing care of the infant to continue unhindered.

These criteria have been taken into consideration during the development of an indirect calorimetry system designed for use in ventilator dependent infants. This paper describes the system and reports the results of technical and clinical evaluation.

The indirect calorimetry system

The system, which is computer driven, consists
Anna Crighton

Correspondence to:

Dr Forsyth.

Accepted 4 November 1991 
of a respiratory mass spectrometer, a mesh pneumotachometer with differential transducer, a three way electromagnetic valve, and minor modifications to normal ventilator circuitry (figure). The principle is similar to previously reported open circuit techniques in that samples of gas are drawn from the inspiratory and expiratory circuits and the oxygen consumption and carbon dioxide production are calculated from the product of the volume of gas passing through the ventilator circuit and the changes in oxygen and carbon dioxide occurring between the two circuits. The data from the mass spectrometer and the pneumotachometer are received by the microcomputer, and oxygen consumption $\left(\mathrm{Vo}_{2}\right)$, carbon dioxide production $\left(\mathrm{VCO}_{2}\right)$, respiratory quotient $(\mathrm{RQ})$, and energy expenditure (EE) are calculated using the Weir equations ${ }^{7}$ :

$\mathrm{Vo}_{2} \mathrm{ml} / \mathrm{min}=\hat{\mathrm{VE} \mathrm{ml}} / \mathrm{min}\left(\mathrm{FIO}_{2}-\mathrm{FEO}_{2}\right)$

$\mathrm{VCO}_{2} \mathrm{ml} / \mathrm{min}=\hat{\mathrm{VE} \mathrm{ml}} / \mathrm{min}\left(\mathrm{FECO}_{2}-\mathrm{FICO}_{2}\right)$

Energy expenditure $(\mathrm{kJ} / \mathrm{min})=\left[3.9 \times \mathrm{Vo}_{2}\right.$ $\left.(1 / \mathrm{min})+1 \cdot 1 \times \mathrm{VCO}_{2}(1 / \mathrm{min})\right] \times 4 \cdot 2$

where $\mathrm{VE}$ is minute ventilation, $\mathrm{FIO}_{2}$ and $\mathrm{FEO}_{2}$ are fractional inspired and expired oxygen, and $\mathrm{FECO}_{2}$, and $\mathrm{FICO}_{2}$ are fractional expired and inspired carbon dioxide.

Each of the measured parameters is graphically displayed in real time on the computer screen. If urine is collected during the study, this enables the measurement of urinary nitrogen which will allow the determination of the non-protein $R Q$, fat, carbohydrate and protein utilisation, ${ }^{8}$ and additional nutritional parameters, which can be calculated by the dedicated software.

\section{Methods}

TECHNICAL EVALUATION

The evaluation of the system was first approached by determining the errors of each of the components of the system. The calculations stated above include three measured values: the volume of gas flow and the concentrations of oxygen and carbon dioxide in the inspiratory and expiratory circuits. The minimum expected error was therefore the sum of the errors sustained in obtaining these specific measurements. Other potential areas of error were the gas sampling process and the effects of varying pressure, humidity, and temperature within the ventilator circuitry. It was also recognised that without a perfect 'gold standard' against which the system could be compared, a component of the systematic error could be due to error in measurement of the gold standard-in this case gas infusion studies-rather than the calorimetry system.

\section{Infant ventilator}

The infants were ventilated with a continuous flow, time cycled infant ventilator (Sechrist Model IV-100B). Depending on the compressible volume of the circuit and the humidifier, a flow rate of $6-81 / \mathrm{min}$ is usually required to achieve adequate peak pressure and pressure rise time. Initial analysis of gases sampled from the inspiratory and expiratory circuits demonstrated that there was contamination of the gas samples taken from the expiratory circuit. This was found to be due to a low pressure flow of gas which, occurring during the exhalation phase, passed from the fluidic control system to the pressure alarm system via the pressure sense line, and this line connected with the patient attachment at the proximal end of the expiratory circuit. This flow of gas was not essential for normal ventilator performance, and after discussion with the distributing company (EME, Brighton) this gas flow was disconnected.

\section{Flow measurements}

The flow through the ventilator circuit was measured by a mesh type pneumotachometer which was situated in the inspiratory circuit, proximal to the humidifier. The pneumotachometer was connected to a differential pressure transducer (Airspec), which had an output of $5 \mathrm{~V}$ for $12 \mathrm{l} / \mathrm{min}$ and linearisation over a range of $0-12 \mathrm{l} / \mathrm{min}$. Calibration of the pneumotachometer was undertaken using a calibrated syringe and a previously described computerised method which determines the conductance characteristics of the flowmeter. ${ }^{12}$ The conductance values of the pneumotachometer correspond to pressure values which are determined by a weighted averaging technique, following multiple strokes of the precision calibrated syringe. The conductance values allow the measured differential pressures to be converted point to point into flows. The precision of repeated calibrations was $\pm 0 \cdot 3 \%$ of the syringe

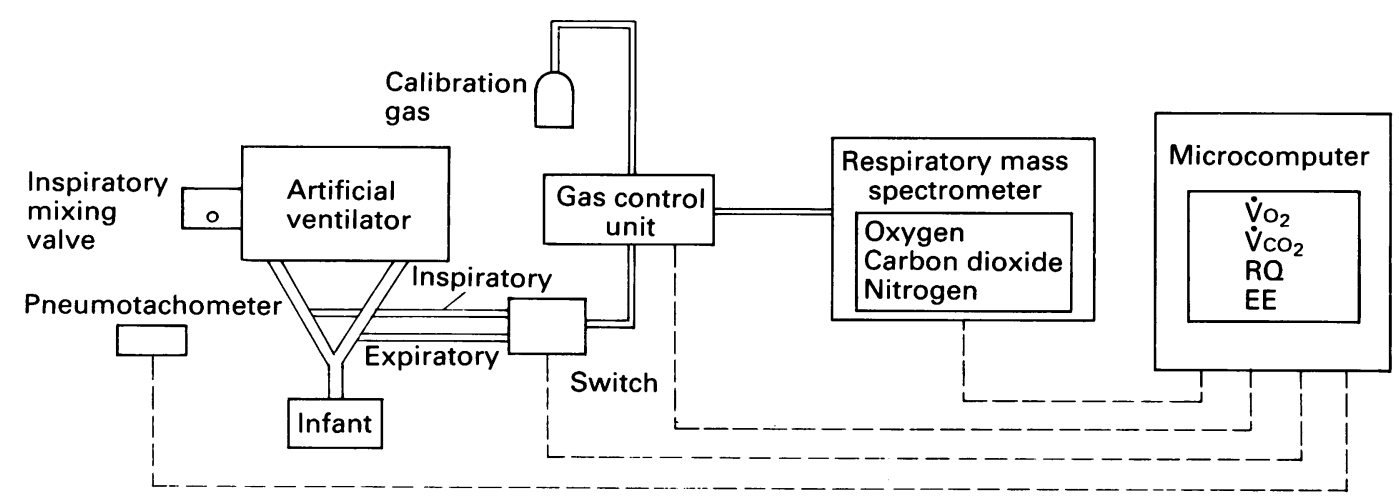


volume using a 50 stroke calibration process. The accuracy of measured volumes was shown to be within $\pm 0.5 \%$ after a 100 stroke calibration process. Calibration was performed using room air, and as the pneumotachometer is situated proximal to the humidifier, the effect of the difference in temperature, humidity, and pressure from ventilation gas was considered to be minimal.

\section{Connections}

Gas samples of approximately $100 \mathrm{ml} / \mathrm{min}$ were obtained through access points within the inspiratory and expiratory circuits and transmitted through capillaries to a standard miniature three way electromagnetic valve (Airspec), which was operated by computer control. The sampling times for inspiratory and expiratory gas can be individually programmed and in the reported clinical studies the inspiratory time was 12 seconds and expiratory time 38 seconds. The valve directed the sample gas through a single capillary to the mass spectrometer. With both inspiratory and expiratory samples being fed in turn to the mass spectrometer through a common capillary, the effects of pressure sensitivity on the analyses were removed.

\section{Mass spectrometer}

Paramagnetic oxygen analysers and infrared carbon dioxide analysers require gas samples to pass through a drying chamber before analysis. This produces a significant delay in the response time, and therefore accurate synchronisation of the time of analysis with the collection time is necessary. This potential error can be avoided by measuring oxygen and carbon dioxide by mass spectrometry. With this method the gases are measured directly and the response time is such that the measurements can be considered immediate and simultaneous. In this system a quadrupole mass spectrometer, (Airspec MGA 2000) was used. Factory evaluation of this instrument showed that reproducibility was better than $1 \%$ of value, drift was less than $1 \%$ in 24 hours, and linearity was better than $1 \%$ for uncorrected data. This instrument has a measurement resolution of 12 bits for $10 \mathrm{~V}$, and in the slow mode each gas is analysed every $20 \mathrm{~ms}$ with each data acquisition being the average of 256 measurements. The procedure of tuning and calibration of gases can be undertaken manually, or remotely by computer control. In this application the mass spectrometer was tuned to measure the concentration of oxygen, carbon dioxide, argon, and nitrogen.

\section{Systematic error}

Initial validation studies of the complete system were undertaken using a dummy lung configuration. The dummy lung was a 0.5 litre rebreathing bag ( $M$ and IE Dentsply) and this was ventilated with settings similar to those required by an infant with moderately severe respiratory disease-rate $40 / \mathrm{min}, \mathrm{FIO}_{2} 40 \%$, and inspiratory and expiratory pressures $20 / 4 \mathrm{~cm}$ $\mathrm{H}_{2} \mathrm{O}$. The aims of this part of the evaluation were to determine drifts in measurement of oxygen and carbon dioxide concentration over time, and to confirm zero gas exchange with this non-breathing system. Over the 24 hour study period drifts in oxygen concentration of $\pm 0.5 \%$ were recorded and the carbon dioxide concentration remained within $\pm 0.02 \%$. To counteract the effect of possible drift on the calculations, the values taken for inspiratory gas concentrations were the mean of the measurements taken before and after expiratory sample. With this modification, the mean $\mathrm{Vo}_{2}$ and $\mathrm{VCO}_{2}$ measured using the dummy lung configuration over 24 hours was $0 \cdot 0( \pm 0 \cdot 1)$.

To assess the ability of the system to measure accurately the gas exchange, gas infusion studies were designed to simulate the levels of carbon dioxide production and oxygen consumption that are likely to occur in sick premature infants. The ventilator settings during the infusion studies were as described above. In each case the relevant test gas was infused into the inspiratory circuit by a peristaltic infusion pump P-3 (Pharmacia). The peristaltic pump was used in preference to a continuous flowmeter because the former emitted the gases in pulses and was therefore more accurately simulating the intermittent nature of respiration. The flow rate of the pump was measured at regular intervals throughout each study period by infusing the gas into a previously calibrated $U$ shaped water manometer and, from the volume of water displaced over a measured period of time, the flow rate was calculated. The time periods were measured by a hand held stopwatch with a precision of 0.01 seconds. The random error of the time measurement was assessed by recording repeated time measurements for the same displacement of water $(7 \mathrm{ml})$. The mean (SD) of 20 measurements was $14.92(0 \cdot 11)$ seconds with the coefficient of variation $(\mathrm{CV})$ of $<0.75 \%$. The method of timing was therefore sufficiently precise.

The use of the water manometer provided the additional advantage of allowing the measurement of the gas flow to be performed against a pressure similar to that experienced when infusing into the ventilator circuit-that is $4-20 \mathrm{~cm}$ $\mathrm{H}_{2} \mathrm{O}$. Saturation of the water with the infused gases was considered, but thought unlikely to occur, as the duration of infusion of gas through the manometer was always less than 60 seconds. However, this was investigated by infusing oxygen, carbon dioxide, and nitrogen over longer periods of time in order to identify changes in calculated flow rate. The flow rates were unchanged with time and the effect of any saturation was therefore considered to be negligible.

The results of the gas infusion studies are shown in table 1. The carbon dioxide infusion $\left(\dot{\mathrm{W}} \mathrm{CO}_{2}\right)$ directly simulates carbon dioxide production $\left(\mathrm{VCO}_{2}\right)$. Nitrogen infusions simulate oxygen consumption by creating an oxygen difference, which in gas exchange formulas is equivalent to oxygen consumption $\left(\mathrm{Vo}_{2}\right)$. Using the measurements obtained during the infusion, the volume of nitrogen infused $\left(\dot{\mathrm{W}}_{2}\right)$ and 'oxygen consumption' can be calculated. 
Table 1 Gas infusion studies

\begin{tabular}{|c|c|c|c|c|c|c|c|c|c|c|}
\hline Infusion & $\begin{array}{l}\text { Flow } \\
\text { in } \mathrm{ml} / \mathrm{min}\end{array}$ & $\begin{array}{l}\text { Measured } \dot{V} \mathrm{CO}_{2} \\
\text { in } \mathrm{ml} / \mathrm{min}(S D)\end{array}$ & $\% C V$ & $\begin{array}{l}\% \text { Relative } \\
\text { error }\end{array}$ & $\begin{array}{l}\text { Measured } \dot{V} o_{2} \\
\text { in } \mathrm{ml} / \mathrm{min}(S D)\end{array}$ & $\% C V$ & $\begin{array}{l}\% \text { Relative } \\
\text { error }\end{array}$ & $\begin{array}{l}\text { Calculated nitrogen } \\
\text { in } \mathrm{ml} / \mathrm{min}(S D)\end{array}$ & $\% C V$ & $\begin{array}{l}\% \text { Relative } \\
\text { error }\end{array}$ \\
\hline Carbon dioxide & $\begin{array}{r}3 \cdot 86 \\
9 \cdot 20 \\
13 \cdot 98\end{array}$ & $\begin{array}{c}3.80(0.23) \\
9.0(0.13) \\
13.83(0.53)\end{array}$ & $\begin{array}{l}6 \cdot 0 \\
1 \cdot 4 \\
3 \cdot 8\end{array}$ & $\begin{array}{l}-1 \cdot 5 \\
-1 \cdot 2 \\
-1 \cdot 1\end{array}$ & 二 & - & E & - & - & E \\
\hline Oxygen & $\begin{array}{c}7 \cdot 5 \\
9 \cdot 36 \\
14 \cdot 80\end{array}$ & - & 二 & - & 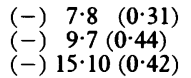 & $\begin{array}{l}4 \cdot 0 \\
2 \cdot 8 \\
2 \cdot 0\end{array}$ & $\begin{array}{l}4 \cdot 1 \\
4 \cdot 3 \\
2 \cdot 0\end{array}$ & - & - & E \\
\hline Nitrogen & $\begin{array}{l}10 \cdot 10 \\
14 \cdot 10\end{array}$ & 二 & - & - & $\begin{array}{c}1.90(0.1) \\
5.45(0.49)\end{array}$ & $\begin{array}{l}5 \cdot 3 \\
8 \cdot 9\end{array}$ & - & $\begin{array}{r}9 \cdot 95(0.41) \\
14 \cdot 20(0 \cdot 82)\end{array}$ & $\begin{array}{l}4 \cdot 1 \\
5 \cdot 7\end{array}$ & $\begin{array}{r}-1.5 \\
1.4\end{array}$ \\
\hline
\end{tabular}

Relative error $=\frac{\text { calculated value }- \text { true value }}{\text { true value }} \times 100 \%$.

Table 2 Clinical studies on ventilated infants. Values as mean (SD)

\begin{tabular}{|c|c|c|c|c|c|c|c|c|c|c|c|c|}
\hline & \multicolumn{4}{|c|}{ Biological data } & \multicolumn{2}{|c|}{ Ventilation } & \multicolumn{2}{|c|}{ Nutritional intake } & \multicolumn{4}{|l|}{ Calorimetry } \\
\hline & $\begin{array}{l}\text { Birth } \\
\text { weight } \\
\text { (g) }\end{array}$ & $\begin{array}{l}\text { Gestation } \\
\text { (weeks) }\end{array}$ & $\begin{array}{l}\text { Age } \\
\text { (days) }\end{array}$ & $\begin{array}{l}\text { Weight } \\
(g)\end{array}$ & $\begin{array}{l}\text { Ratel } \\
\text { min }\end{array}$ & $\begin{array}{l}\% \\
\mathrm{FIO}_{2}\end{array}$ & $\begin{array}{l}\text { Energy } \\
\text { intake } \\
\text { (kf/kg/ } \\
24 \text { hours) }\end{array}$ & $\begin{array}{l}\text { Protein } \\
\text { intake } \\
\text { (g/kg/ } \\
24 \text { hours) }\end{array}$ & $\begin{array}{l}\text { Energy } \\
\text { expenditure } \\
\text { (kf/kg/ } \\
24 \text { hours) }\end{array}$ & $\begin{array}{l}\dot{V} \mathrm{o}_{2} \\
(\mathrm{ml} / \mathrm{kg} / \\
\mathrm{min})\end{array}$ & $\begin{array}{l}\dot{V} \mathrm{co}_{2} \\
(\mathrm{ml} / \mathrm{kg} / \\
\mathrm{min})\end{array}$ & $R Q$ \\
\hline $\begin{array}{l}\text { Total parental } \\
\text { nutrition }(n=5)\end{array}$ & $1286(125)$ & $28 \cdot 8(2 \cdot 0)$ & $5(0 \cdot 7)$ & $1126(159)$ & $30(20)$ & $32(6 \cdot 5)$ & $315(23)$ & $2 \cdot 1(0 \cdot 6)$ & $177 \cdot 6(36)$ & $5 \cdot 80(1 \cdot 10)$ & $6 \cdot 17(1 \cdot 50)$ & $1 \cdot 07(0 \cdot 16)$ \\
\hline $\begin{array}{l}\text { Intravenous } \\
\text { dextrose }(n=5)\end{array}$ & $1862(522)$ & $30 \cdot 2(3 \cdot 3)$ & $2 \cdot 4(1 \cdot 3)$ & $1843(593)$ & $41 \cdot 4(25)$ & $30 \cdot 4(8 \cdot 8)$ & $194(11)$ & - & $147 \cdot 9(24)$ & $4 \cdot 66(0 \cdot 80)$ & $5 \cdot 72(0 \cdot 80)$ & $1 \cdot 13(0.08)$ \\
\hline
\end{tabular}

$$
\dot{\mathrm{W}}_{\mathrm{N}_{2}}=\frac{\dot{\mathrm{V}}\left(\mathrm{FIO}_{2}-\mathrm{FEO}_{2}\right)}{\mathrm{FEO}_{2}}
$$

where $\dot{W}_{N_{2}}$ is the volume of nitrogen infused, and $V$ is flow volume per minute.

$$
\dot{\mathrm{Vo}}_{2}=\left(\dot{\mathrm{V}}_{1} \times \mathrm{FIO}_{2}\right)-\left(\dot{\mathrm{V}}_{2} \times \mathrm{FEO}_{2}\right)
$$

$\dot{V}_{1}$ is inspiratory flow volume per minute, and $\dot{V}_{2}$ is the expiratory flow volume-that is $\dot{\mathrm{V}}_{1}+\dot{\mathrm{W}}_{\mathrm{N}}$.

As a more direct method of measuring small oxygen differences between inspiratory and expiratory samples, oxygen infusions were undertaken. In this test lung configuration the increased oxygen concentration was present in the expiratory sample, producing a measurable 'negative' oxygen consumption, which was calculated as shown above. Each gas infusion was a minimum of $60 \mathrm{~min}$ duration (range 60-90 $\mathrm{min}$ ) and the means, SD and, CV were calculated on a minimum of 40 data points (table 1).

\section{CLINICAL STUDIES}

Clinical evaluation was undertaken on 10 preterm ventilated infants and the results are summarised in table 2 . The infants have been divided into those receiving total parenteral nutrition and those who were receiving dextrose infusion. The mean energy expenditure of all the infants studied was $161 \cdot 7 \mathrm{~kJ} / \mathrm{kg} / 24$ hours, with the lowest measurement of $120 \cdot 8 \mathrm{~kJ} / \mathrm{kg} / 24$ hours) being in an infant of 28 weeks' gestation who was paralysed with a muscle relaxant. The mean RQ was greater than 1.0 in both groups.

The possibility of respiratory gases bypassing the endotracheal tube was investigated at the start of each study by placing the capillary adjacent to the nose and the mouth of the infant. If carbon dioxide and/or oxygen were detected then a flow through technique, using a canopy which completely enclosed the infant, was undertaken. The only difference from the ventilator system was that the inspiratory capillary sampled air entering the canopy and the expiratory capillary sampled the air leaving the canopy. This was undertaken at the start and finish of the studies, and the mean of the results included in the overall calculations. The extratracheal $\mathrm{Vo}_{2}$ ranged from $-0 \cdot 1$ to $+0 \cdot 2 \mathrm{ml} / \mathrm{min}$ and $\mathrm{VCO}_{2}$ from 0.0 to $+0.2 \mathrm{ml} / \mathrm{min}$. In $5 / 10$ infants there was no bypassing of the endotracheal tube.

\section{Discussion}

An indirect calorimetry system for measuring energy expenditure and nutrient utilisation in sick ventilator dependent infants is described. Evaluation of the system showed there was no significant bias, and the instruments used were precise and accurate. Total system error during the worst test conditions was $<5 \cdot 0 \%$. The inspiratory oxygen concentration during the studies was $40 \%$ and therefore the ratio of signal to noise very small during the studies with the low oxygen flows, but even in those conditions a relative error of $4 \%$ and coefficient of variation $4 \%$ would indicate that the system has adequate precision and accuracy to be used in the sickest infants.

The principle objectives of the system have been achieved in that it is non-invasive, compatible with continuous flow infant ventilators, and operates without inconveniencing medical or nursing care. Studies of energy expenditure can continue for $\mathbf{2 4}$ hours or longer and can start from the moment the infant is placed on the ventilator.

The rapid response time of the analyses and the real time graphic display enables the acute and chronic effects of procedures and medications on energy expenditure and nutrient utilisation to be studied. The management of 
the sick premature infant involves a number of interventions which are likely to influence the energy balance and nutritional status of the infant-in particular, the administration of surfactant, dexamethasone, and transfusion of blood.

Failure to capture all of the expired respiratory gases is a potential source of error with this method. It is also possible that ventilator gas may leak from the distal end of the endotracheal tube without entering the infant's lower respiratory tract, thus producing a falsely high measurement for oxygen consumption. Leakages are less likely in the more premature infants and those infants who have had an endotracheal tube in situ for a short time. Our findings were similar to those of Lucas and colleagues who found that bypassing of the endotracheal tube occurred in less than half the infants studied and was not more than 0.2 $\mathrm{ml} / \mathrm{min}$ for carbon dioxide. ${ }^{13}$ In our studies we detected that the maximum leakage for both oxygen and carbon dioxide was $0.2 \mathrm{ml} / \mathrm{min}$. The contribution of the skin to gas exchange has previously been reported as being up to $15 \%$ in the smallest infants. ${ }^{14}$ For these reasons we introduced our canopy method in which the whole infant was enclosed and the results obtained are thought to reflect all extratracheal gaseous exchange. Ideally, the canopy method should run simultaneously with sampling from the ventilator circuits and this may be possible with the aid of a multiplex valve, but this has yet to be tested. Modified face masks have been used to collect intratracheal and extratracheal gases, ${ }^{15}$ but the placement of a mask on the face of an infant interferes with normal nursing care, and because of its invasiveness may have an independent influence on the results obtained.

The clinical studies confirmed that the system did not affect the respiratory management of the infant, and normal nursing and medical procedures were able to be undertaken. Preliminary results indicate that energy expenditure may be lower than previously suspected. This is likely to be due to the decrease in the work of breathing and also because of the reduced activity of the sick premature infant. More formal studies are now in progress to confirm these findings.

The respiratory quotient was generally greater than 1.0 and was particularly high in some infants receiving intravenous dextrose alone. It has been demonstrated in adults that a high intravenous carbohydrate intake results in carbohydrate being converted to fat, and this process results in a considerable increase in carbon dioxide production. ${ }^{16}$ In order to eliminate this additional carbon dioxide, infants are likely to require increased ventilator support: in our study the infant with the highest RQ was being ventilated with air because of persistent carbon dioxide retention. Thus, a more appropriate parenteral nutrition regimen may not only improve the growth and development of the infant but also reduce the degree and duration of ventilator support.

The authors wish to acknowledge the support they have received from Cow and Gate Ltd and the Gannochy Trust, and the invaluable technical assistance from Mr David Avery, Chest Scientific Instruments Ltd.

1 Anonymous. Scottish neonatal statistics 1985. Edinburgh: Information Services Division. Common Services Agency, Scottish Health Service, 1985.

2 Marlow N, D'Souza SW, Chiswick ML. Neurodevelopmenta outcome in babies weighing less than $2001 \mathrm{~g}$ at birth. $B M F$ 1987;294:1582-6.

3 Social Paediatric and Obstetric Research Unit. Scottish low birthweight study. Glasgow: Social Paediatric and Obstetric Research Unit, University of Glasgow, September 1989.

4 Tyson J, Lasky R, Mize C, White R. Growth and development of infants less than $1500 \mathrm{~g}$ fed bank human milk or premature formula (abstract). Pediatr Res 1981;15:549: premature

5 Lucas A, Morley R, Cole TJ, et al. Early diet in preterm babies and developmental status in infancy. Arch Dis Child 1989;64:1570-8.

6 Reichman B, Chessex B, Verellen G, et al. Dietary composition of macronutrient storage in preterm infants. Pediatrics 1983;72:322-8.

7 Weir JB de V. New methods for calculating metabolic rate with special reference to protein metabolism. I Physiol (Lond) 1949;109:1-9.

8 Westenskow DR, Schipke CA, Raymond JL, et al. Calculation of metabolic expenditure and substrate utilisation from gas exchange measurements. foumal of Parenteral and Enteral Nutrition 1988;12:20-4.

9 Wharton BA. Nutrition and feeding of preterm infants. Oxford: Blackwell Scientific Publications, 1987.

10 Pineault $M$, Chessez $P$, Bisaillon $S$, Brisson G. Total parenteral nutrition in the newborn: impact of the quality parenteral nutrition in the newborn: impact of the quality of infused energy

11 Stoner HB. Why is energy expenditure increased by trauma and sepsis? Care of the Critically IIl 1987;3:108-9.

12 Yeh MP, Gardner RM, Adams TD, Yanowitz FG. Com puterised determination of pneumotachometer characteristics using a calibrated syringe. Fournal of Applied Physiology: Respiratory, Environmental and Exercise Physiology 1982;53. $280-5$.

13 Lucas A, Nohria V, Roberts SB. Measurement of carbon dioxide production rate in sick ventilated premature infants. Biol Neonate 1987;51:138-43.

14 Cartilage PHT, Rutter N. Percutaneous carbon dioxide excretion in the newborn infant. Early Hum Dev 1990;21: 93-103.

15 Hammerlung K, Sedin G. Can respiratory water loss and oxygen consumption be measured accurately during ventilator and CPAP treatment. Pediatr Res 1990;28:286:abst 56.

16 Askanazi J, Rosenbaum SH, Hyman AI, Silverberg PA, Milic-Emili J, Kinney JM. Respiratory changes induced by the large glucose loads of total parenteral nutrition. $\mathcal{F} A M A$ 1980;243:1444-7. 